\title{
Development of natural and unnatural amino acid delivery systems against hookworm infection
}

Stacey Bartlett ${ }^{1}$, Mariusz Skwarczynski ${ }^{1}$, Xin Xie ${ }^{1}$, Istvan Toth ${ }^{1,3,4}$, Alex Loukas ${ }^{2 \#}$, Ramon M. Eichenberger $^{2 \# *}$.

${ }^{1}$ The University of Queensland, School of Chemistry and Molecular Biosciences, St Lucia QLD 4072, Australia

${ }^{2}$ James Cook University, Centre for Molecular Therapeutics, Australian Institute of Tropical Health and Medicine, Cairns, QLD 4878, Australia

${ }^{3}$ The University of Queensland, School of Pharmacy, Woolloongabba, QLD 4102, Australia

${ }^{4}$ The University of Queensland, Institute for Molecular Biosciences, St Lucia, QLD 4072, Australia

\section{Graphical abstract}

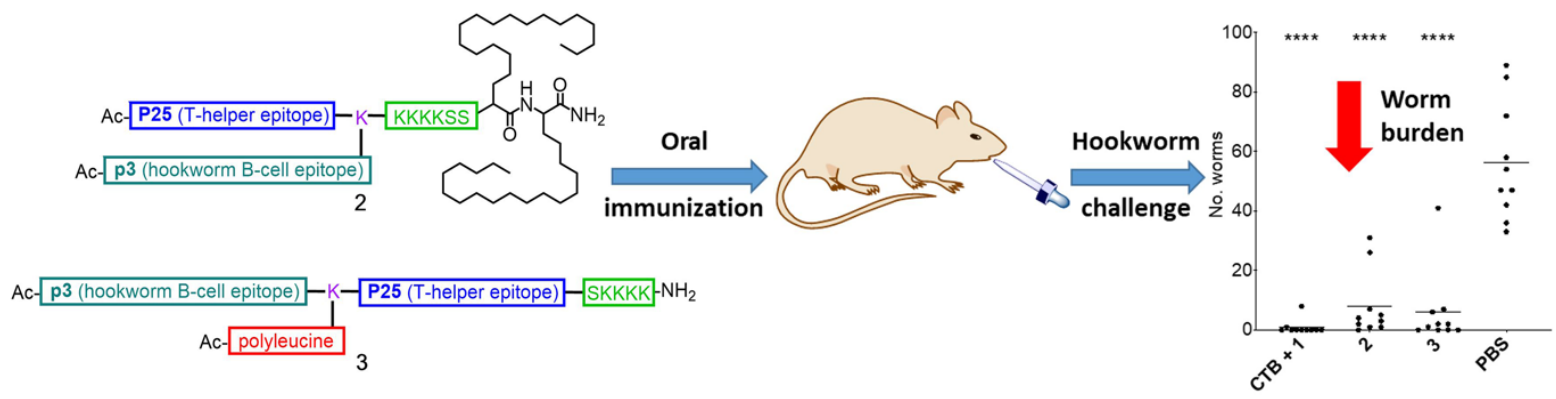

\section{Abstract}

Peptide-based vaccines consist of short antigen fragments derived from a specific pathogen. Alone, these peptide fragments are poorly or non-immunogenic; however, when incorporated into a proper delivery system, they can trigger strong immune responses. To eliminate the need for toxic and often ineffective oral adjuvants, we designed single molecule-based self-adjuvating vaccines against hookworms using natural and unnatural hydrophobic amino acids. Two vaccine conjugates were synthesized, consisting of B-cell epitope p3, derived from the hookworm Na-APR-1 protein; universal T-helper peptide P25; and either double copies of unnatural lipoamino acid (2-amino-D,L-eicosanoic acid), or ten copies of the natural amino acid leucine. After challenge with the model hookworm, Nippostrongylus brasiliensis, mice orally immunized with the conjugates, but without adjuvant, generated antibody responses against the hookworm epitope, resulting in significantly reduced worm and egg burdens compared to control mice. We have demonstrated that vaccine nanoparticles composed exclusively of natural amino acids can be effective even when administered orally.

\section{Keywords}

amino acid polymer, peptide vaccine, hookworm, APR-1 protein epitope, oral delivery, lipopeptide, poly(amino acids), parasite challenge, self-assembled nanoparticles

\section{Abbreviations}

- DIPEA: $N, N^{\prime}$-diisopropylethylamine

- HATU: (dimethylamino)- $N, N$ dimethyl $(3 \mathrm{H}-[1,2,3]$ triazolo[4,5-

b]pyridin-3-yloxy)-methanim-inium hexafluorophosphate
- LAAs: lipoamino acids

- LCP: lipid core peptide

- HAAs: hydrophobic amino acids

- pHAAs: poly(hydrophobic amino acids)

- GIT: gastrointestinal tract

- DLS: dynamic light scattering

- CTB: cholera toxin subunit B

\footnotetext{
*Corresponding Author: Ramon M. Eichenberger: ramon.eichenberger@uzh.ch
}

\# Equally contributing senior authors 


\section{Rational and purpose}

Low immunogenicity of peptide vaccines, especially following oral administration, is an important hurdle in their development. Designing a vaccine delivery system without toxic and often ineffective oral adjuvants is important for the control of hookworm in endemic areas. The purpose of this study was to develop oral, single molecule-based selfadjuvating vaccines against hookworms using natural and unnatural hydrophobic amino acids.

\section{Introduction}

Necator americanus is the most prevalent human hookworm, infecting more than 0.4 billion people. The intestinal parasite attaches to the mucosa of the small intestine with its teeth or cutting plate and feeds on blood and mucosal tissue. The parasite can cause longterm pathological issues, such as irondeficiency anaemia, which can lead to impaired neurological and cognitive function in chronically infected infants. Globally, hookworm infection is one of the most common tropical diseases, outranking dengue fever, schistosomiasis and leprosy in terms of disability-adjusted life-years. ${ }^{1}$ Current treatment for hookworms involves mass administration of anthelminthic drugs, such as albendazole and mebendazole, to school-aged children in endemic regions. While chemotherapy is generally effective, reduced drug efficacy, continuous reinfection and the wide distribution of hookworms has prompted the need for alternative strategies to control infection. ${ }^{1}$ Intriguingly, life-long exposure to hookworm infection does not stimulate robust protective immunity, since worm burden is often heaviest in the elderly. ${ }^{2}$ Furthermore current efforts to develop a hookworm vaccine have not been successful.

Peptide-based vaccines have the potential to overcome the limitations of classical wholepathogen vaccines. This includes the prevention of allergic and autoimmune responses and overcomes the difficulty in producing essential biological materials. ${ }^{3}$ Peptide vaccines consist of short, defined, synthetic epitopes derived from a specific target pathogen. They can be easily synthesized and purified in large-scale using purely chemical methods, avoiding any biological contamination. However, peptides are not stable in vivo and are poorly immunogenic, lacking the danger signals needed for recognition by the immune system. Thus, peptide antigens need to be incorporated into an appropriate delivery/adjuvant system. ${ }^{4,5}$

Unnatural amino acids, such as lipoamino acids (LAAs), have been widely used in the lipid core peptide (LCP) system to generate immune responses against a variety of pathogens, ${ }^{6-11}$ including hookworm. ${ }^{12,}{ }^{13}$ LCP consists of peptide epitopes, a branching moiety, and LAAs incorporated together into a single molecule. LCPs can self-assemble into nanoparticles using the amphiphilic properties of the lipid peptide conjugates. ${ }^{14}$ Nanoparticles are particularly attractive in vaccine design, ${ }^{15,16}$ as they can be effectively taken up by antigenpresenting cells, stimulate adaptive immunity and have improved oral stability. ${ }^{17-20} \mathrm{We}$ demonstrated previously that LCP nanoparticles can be effective in inducing the production of high antibody titers against Group A Streptococcus (GAS) infection. ${ }^{21,22}$

Upon conjugation with a peptide antigen, polymerized natural hydrophobic amino acids (HAA) could also form amphiphiles, which were able to self-assemble into nanoparticles. ${ }^{14}$ Poly-HAAs (pHAAs) were produced through classical solid-phase peptide synthesis, which allowed their and peptide antigens incorporation into one molecule in a single procedure. Key advantages of this system were improved biodegradability and biocompatibility as well as the ability to adjust the properties of the pHAA unit (solubility, conformation, etc.) as required by changing the type and number of incorporated HAAs. While we recently demonstrated that the pHAA system can self-assemble into chain-like nanoparticle aggregates and serve as an injectable vaccine against $\mathrm{GAS},{ }^{23}$ the ability of such a system to deliver antigens orally has not yet been investigated.

Most commercially available vaccines require administration through invasive and inconvenient techniques that could result in low patient compliance and need to be delivered by professional medical staff in remote areas where neglected tropical diseases prevail. Oral delivery has been shown to have many advantages over invasive delivery methods. These include the capacity for selfadministration, which greatly reduces the cost 
of vaccination campaigns, simplified production and storage procedures/infrastructure, and improved efficacy against gastrointestinal tract (GIT) pathogens. ${ }^{17,} 24$ Oral vaccines, however, are exposed to the bacteria, proteolytic enzymes and low $\mathrm{pH}$ of the GIT, which can degrade peptides. Therefore, effective oral delivery of antigens usually requires dietary changes, advanced administration of alkalisers and multiple doses, which could induce oral tolerance and reduce patient compliance. So far, several oral vaccines have been licensed; however, they are all composed of whole pathogens (inactivated and live-attenuated). Labile antigens, such as peptides, are yet to be successfully used in oral vaccines.

Promising anti-hookworm vaccine candidates are under development based on Na-APR-1, the cathepsin D-like aspartic protease that is responsible for the degradation of human haemoglobin, which the worms use as nourishment. ${ }^{25,26}$ These vaccines were designed to stimulate the production of neutralizing antibodies to inhibit $\mathrm{Na}$-APR-1 activity during hookworm blood feeding in the host intestine. Problems with scale-up of protein production and its aggregation ${ }^{27}$ prompted the discovery of a synthesizable peptide derived from $\mathrm{Na}$-APR1, called $\mathrm{A}_{291} \mathrm{Y}$, which was the target of monoclonal antibodies that neutralize the proteolytic activity of the parent $N a$-APR-1 protein. ${ }^{28} \mathrm{We}$ established that a 22-mer peptide derived from $\mathrm{A}_{291} \mathrm{Y}$, called $\mathrm{p} 3$, when lipidated or mixed with adjuvant, stimulated the production of Na-APR-1 proteolysisneutralizing antibodies upon subcutaneous immunisation. ${ }^{12}$, 13 We then further demonstrated that a mixture of $\mathrm{p} 3$-bearing lipopeptides forming rod-like nanoparticles and anchored to sodium alginate/trimethyl chitosan-coated liposomes could stimulate hookworm neutralizing immune responses upon oral administration. ${ }^{29}$

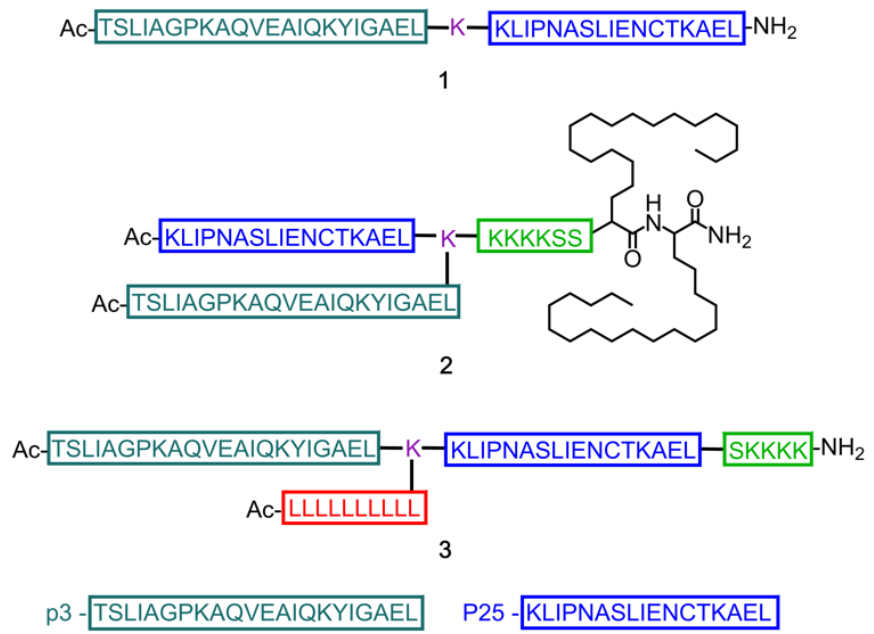

Figure 1. Schematic representation of vaccine peptides 1, 2 and 3. Vaccine candidates consisted of 3 peptide derived from hookworms, and T-helper P25 (1), conjugated to an LCP delivery system with KKKKS peptide as hydrophilic linker (2) or conjugated to a polyleucine delivery system with the same linker (3).

\section{Experimental design}

Here, we aimed to create a simple, single molecule-based self-adjuvating oral vaccine against hookworm infection. We designed two vaccine candidates with peptide antigens conjugated to either unnatural lipidic LAA or natural pHAA units. The $\mathrm{p} 3$ hookworm B-cell epitope was coupled to a T-helper peptide (P25) with a lysine branching spacer (1) and attached to an LCP system containing 2-amino-D,Leicosanoic acid ${ }^{21}$ to produce lipopeptide (2) and a pHAA delivery system containing polyleucine to produce peptide (3) (Figure 1). The vaccine candidate's efficacy was examined in the mouse model using antibody titers and parasite challenge. The hookworm responsible for human infection, $N$. americanus, does not naturally infect laboratory animals. Therefore, to determine the antigenicity and vaccine efficacy of the conjugates, the soil-transmitted nematode $N$. brasiliensis ("rodent hookworm") was used for animal experiments. $N$. 
brasiliensis has a similar lifecycle and morphology to the human hookworm, and its secretome is highly conserved with that of $N$. americanus. Of particular note, the $\mathrm{p} 3$ peptide of $\mathrm{Na}$-APR-1 is completely conserved between the two parasites. ${ }^{29}$

\section{Materials and methods}

\section{Materials}

All chemical materials used in this study were analytical grade unless otherwise stated.

Protected Fmoc amino acids and [(1bis(dimethylamino) methylene]-1H-1,2,3triazolo[4,5-b] pyridinium 3-oxid hexafluorophosphate (HATU), were purchased from Mimotopes (Melbourne, Australia). Rinkamide $p$-methylbenzhydrylamine (MBHA) resin was purchased from Novabiochem (Hohenbrunn, Germany). Dichloromethane (DCM), diethyl ether, piperidine, trifluoroacetic acid (TFA), $N, N^{\prime}$ dimethylformamide (DMF), HPLC grade acetonitrile and methanol were purchased from Merck (Darmstadt, Germany). N, $N^{\prime}$ diisopropylethylamine (DIPEA), triisopropylsilane (TIS), acetic anhydride, cholera toxin B subunit (CTB), phosphatebuffered saline (PBS), goat anti-mouse IgG and goat anti-mouse IgA conjugated to horseradish peroxidase and 3,3',5,5'tetramethylbensidine (TMB) substrate were purchased from SigmaAldrich (St Louis, USA). All other reagents were purchased from Sigma-Aldrich (Castle Hill, NSW, Australia).

\section{Synthesis of Peptide 1}

Peptide 1 was synthesised at $0.1 \mathrm{mmol}$ on rink amide MBHA resin using Fmoc-SPPS, as per the standard protocol. ${ }^{30}$ In summary, resin (substitution ratio: $0.79 \mathrm{mmol} / \mathrm{g}, 0.1 \mathrm{mmol}$ scale, $0.127 \mathrm{~g}$ ) was swelled overnight in DMF. Synthesis was carried out by microwaveassisted Fmoc-SPPS, using the SPS mode on a CEM Discovery reactor. The Fmoc group was removed using $20 \%$ piperidine/DMF for 2 and 5 minutes at $70^{\circ} \mathrm{C}$. Amino acids were activated with $0.5 \mathrm{M}$ 1-[bis(dimethylamino)methylene]1H-1,2,3-triazolo[4,5-b] pyridinium 3-oxid hexafluorophosphate (HATU) (4 equiv, 0.8 $\mathrm{mL}$ ) and $N, N$-diisopropylethylamine (DIPEA) (5.2 equiv, $91 \mu \mathrm{L}$ ) in DMF and added to the resin for 5 and 10 minutes of coupling. Unreacted resin was acetylated with acetic anhydride, DIPEA and DMF (5:5:90) at $70^{\circ} \mathrm{C}$, twice (5 minutes and 10 minutes). The remaining amino acids were coupled in the same manner. The peptide was cleaved from the resin using a mixture of TFA:TIS:water $(95: 2.5: 2.5)$.The lipopeptide was dissolved in solvent B (acetonitrile and water at a ratio of 90:10) prior to lyophilization. The product was purified by RP-HPLC using a C18 Vydac column with a solvent gradient of $45-65 \%$ solvent B over $30 \mathrm{~min}$. Analytical analysis was performed using a Shimadzu instrument (C4 column): $t_{R}=26.0 \mathrm{~min}$, purity $>95 \%$. Yield: $32 \%$. ESI-MS: $\mathrm{m} / \mathrm{z} 1423.6$ (calc 1423.3) $[\mathrm{M}+3 \mathrm{H}]^{3+} ; 1067.8$ (calc 1067.7) $[\mathrm{M}+4 \mathrm{H}]^{4+}$; 854.3 (calc 854.4) $[\mathrm{M}+5 \mathrm{H}]^{5+} ; 701.8$ (calc 701.8) $[\mathrm{M}+6 \mathrm{H}]^{6+}$. MW = 4267.1.

\section{Synthesis of Peptide 2}

Peptide 2 was synthesized at $0.2 \mathrm{mmol}$ using the tert-butyloxycarbonyl (Boc) SPPS technique on MBHA resin in a similar manner as above. Resin (substitution ratio: 0.59 $\mathrm{mmol} / \mathrm{g}, 0.2 \mathrm{mmol}$ scale, $0.34 \mathrm{~g}$ ) was swelled for 2 hours in DMF and DIPEA (5.2 equiv, 91 $\mu \mathrm{L})$. LAA and amino acids were activated with HATU (4 equiv, $0.8 \mathrm{~mL}$ ) and DIPEA (5.2 equiv, $91 \mu \mathrm{L}$ ) in DMF and added to resin for 5and 10-minute couplings. 4,4-dimethyl-2,6dioxycyclohexylidene-2-amino-d,1-eicosanoic acid (Dde-C20-OH) was coupled to the resin using two 1-hour couplings at room temperature. The Dde protecting group was removed from the resin using hydrazine monohydrate $(5 \%)$ for 10,10 , and 20 minutes at room temperature. The remaining amino acids were coupled in the same manner. The Boc protecting group was removed using TFA, twice, for 1 minute each time with stirring at room temperature. Boc-Lys(Fmoc)OH was introduced before synthesis of the P25 sequence allowing for peptide branching. The Fmoc group was removed using $20 \%$ piperidine upon completion of the P25 sequence to allow for branching of the $\mathrm{p} 3$ peptide. The peptide was cleaved from the resin using hydrofluoric acid (HF) $\left(10 \mathrm{mLHF} / \mathrm{g}\right.$ resin) at $-8^{\circ} \mathrm{C}$ in the presence of $5 \%(\mathrm{v} / \mathrm{v}) \mathrm{p}$-cresol and $5 \%(\mathrm{v} / \mathrm{v}) \mathrm{p}$ thiocresol. The lipopeptide was dissolved in solvent B prior to lyophilization. The product was purified using RP-HPLC with a $\mathrm{C} 4$ column at a gradient of $45-65 \%$ solvent $\mathrm{B}$ over 30 minutes. $t_{R}=41.1$ min, purity $>95 \%$. Yield: 13\%. ESI-MS: $\mathrm{m} / \mathrm{z} 1886.3$ (calc 1886.6) 
$[\mathrm{M}+3 \mathrm{H}]^{3+} ; 1415.6($ calc 1415.2$)[\mathrm{M}+4 \mathrm{H}]^{4+}$; 1132.5 (calc 1132.4) $[\mathrm{M}+5 \mathrm{H}]^{5+}$; 944.0 (calc 943.8) $[\mathrm{M}+6 \mathrm{H}]^{6+} ; 809.3$ (calc 809.1) $[\mathrm{M}+7 \mathrm{H}]^{7+}$. $\mathrm{MW}=5657.0$.

\section{Synthesis of Peptide 3}

Peptide 3 was synthesized at $0.2 \mathrm{mmol}$ using Boc SPPS on MBHA resin in the same manner as that described for peptide $\mathbf{2}$. The initial peptide containing p3 and P25 sequences was synthesized, followed by attachment of the pHAA chain. Boc-Lys(Fmoc)OH was introduced after the synthesis of P25 allowing for peptide branching. Following the synthesis of $\mathrm{p} 3$ to the lysine-P25 sequence, the Fmoc side chain was removed using $20 \%$ piperidine and the poly-leucine moiety was attached using the standard coupling procedure. The product was purified using RP-HPLC with a C4 column at a $40-70 \%$ solvent B gradient over 30 minutes. $t_{R}$ $=30.2 \mathrm{~min}$, purity $>95 \%$. Yield: $16 \%$. ESI-MS: $\mathrm{m} / \mathrm{z} 1522.0$ (calc 1521.6) $[\mathrm{M}+4 \mathrm{H}]^{4+} ; 1217.6$ (calc 1217.5) $[\mathrm{M}+5 \mathrm{H}]^{5+} ; 1014.9$ (calc 1014.7) $[\mathrm{M}+6 \mathrm{H}]^{6+}$. MW $=6082.5$.

\section{Characterization of 2 and 3}

The size of the self-assembled particles was measured by dynamic light scattering using a Zetasizer 3000TM (Malvern Instruments, Malvern, UK). Morphology of the vaccine peptides was evaluated using transmission electron microscopy (TEM) (HT7700 Exalens, HITACHI Ltd., Japan) following vacuum drying. Briefly, the samples were diluted in pure distilled water (1:100), dropped directly on a glow-discharged carbon-coated copper grid, then stained with $2 \%$ uranyl acetate. The samples were observed at $200 \quad 000$ magnification.

\section{Vaccination scheme and hookworm challenge}

Ten-week-old male BALB/c mice (Animal Resources Centre, Perth, WA, Australia) were randomly divided into four groups of 10 . The mice had free access to pelleted food and water. Freshly prepared preparations were orally administered at a dose of $100 \mu \mathrm{g}$ of peptides 2 and 3 in $100 \mu \mathrm{L}$ of water per mouse using a 20gauge oral gavage tube on days $0,7,14,21,28$, and 35. The negative control group received $100 \mu \mathrm{L}$ PBS per mouse, while the positive control group received $100 \mu \mathrm{g}$ control peptide 1 with $10 \mu \mathrm{g}$ of CTB in $100 \mu \mathrm{L}$ of water per mouse, all on the same dosing schedule. Two weeks after the final immunization (day 49), mice were subcutaneously administered with 500 infectious Nippostrongylus brasilisensis larvae (L3) in $200 \mu \mathrm{L}$ PBS in the scruff. $N$. brasiliensis was maintained in Sprague-Dawley rats (Animal Resources Centre), as previously described. ${ }^{31}, 32$ Infectious L3 were freshly prepared from 2-week-old rat faecal cultures. Mice were euthanized with $\mathrm{CO}_{2} 7$ days postinfection. Blood, adult parasites from the small intestine and weighted faecal samples from the large intestine were collected.

\section{Collection of serum}

Blood samples on day 48 were taken from the tail, while samples on day 56 were collected via cardiac puncture euthanasia. All samples were deposited into separation Z-Gel micro tubes (Sarstedt 41.1378.005), left for 1 hour at room temperature, then centrifuged for 5 minutes at $10,000 \mathrm{~g}$. The serum was removed and stored at $-20^{\circ} \mathrm{C}$ until analysis.

\section{Evaluation of antibody responses}

Enzyme-linked immunosorbent assays (ELISAs) were performed to determine antigen-specific IgG antibody titers from serum samples. All reactions were performed in 100 $\mu \mathrm{L} /$ well. Each well of a 96 -well microtiter plate (Greiner Microlon ${ }^{\circledR}$ 600) was coated with 5 $\mu \mathrm{g} / \mathrm{mL}$ of $\mathrm{p} 3$ peptide, mature recombinant $\mathrm{Na}$ APR-1 (provided courtesy of Pearson et al. ${ }^{33}$ ) or $N$. brasiliensis excretory/secretory proteins ( $\mathrm{Nbr}$ ESP; as described by Eichenberger et al. ${ }^{34}$ ) diluted in $0.1 \mathrm{M}$ sodium carbonate/bicarbonate $(\mathrm{pH} 9.6)$ for 2 hours at $37^{\circ} \mathrm{C}$. Plates were washed three times with PBS $/ 0.5 \%$ Tween 20 (PBST) and blocked with 5\% skim milk to reduce non-specific binding overnight at $4^{\circ} \mathrm{C}$. Samples at a 1:100 dilution for $\mathrm{IgG}$ in serum were added for 1 hour at $37^{\circ} \mathrm{C}$. All reactive samples were titrated to endpoint in two-fold serial dilutions. Plates were washed three times and horseradish peroxidase-conjugated goat anti-mouse IgG antibody (1:4000 in PBST, Invitrogen \#62-6) was added for 1 hour at $37^{\circ} \mathrm{C}$. Plates were washed four times and incubated with TMB substrate solution (Invitrogen 004201-56) at room temperature for 20 minutes. Antibody titers from the samples were taken at the lowest dilution that exceeded an absorbance of three standard deviations of the mean absorbance from the negative control group. 


\section{Statistical Analysis}

Statistical analysis of antibody titers between groups was performed using one-way analysis of variance (ANOVA) followed by Tukey's multiple comparisons test. Differences in adult worm and faecal egg burdens were determined by non-parametric Mann-Whitney $U$ test. GraphPad Prism 7.03 software (GraphPad Software Inc., CA, USA) was used for statistical analysis. Differences were considered significant at $p<0.05$.

\section{Results and Discussion}

Peptides 1-3 were synthesized according to the standard Boc-SPPS procedure. $^{35}$ A hydrophilic moiety built from lysine and serine was introduced to peptides $\mathbf{2}$ and $\mathbf{3}$ to increase solubility and promote the self-assembly of peptides as both P25 and p3 are relatively hydrophobic. This moiety is identical to the traditional solubilizing unit used in the
Pam3Cys adjuvant and its derivatives. ${ }^{36} \mathrm{~A}$ similar approach effectively produced selfassembled LCP-based nanoparticles (15-20 $\mathrm{nm}$ ) for a peptide-based vaccine against GAS. ${ }^{37}$

Peptides $\mathbf{2}$ and $\mathbf{3}$ were self-assembled under aqueous conditions. Their properties were measured using dynamic light scattering (DLS) and TEM (Figure 2). Peptide 2 formed particles of around $115 \mathrm{~nm}$ and $340 \mathrm{~nm}$ in size with a high polydispersity index (PDI) of 0.4 , similar to random aggregates previously seen in LCPbased systems. ${ }^{38-40}$ Peptide $\mathbf{3}$ displayed a range of particle sizes $(100-5000 \mathrm{~nm})$ with a PDI of 0.4; however, $100 \mathrm{~nm}$ nanoparticles were predominantly observed through TEM (Figure 2). Particle size can affect absorption through the GI tract and, subsequently, recognition and processing by antigen presenting cells; particles less than $500 \mathrm{~nm}$ are taken up more efficiently than larger particles. ${ }^{17,41}$
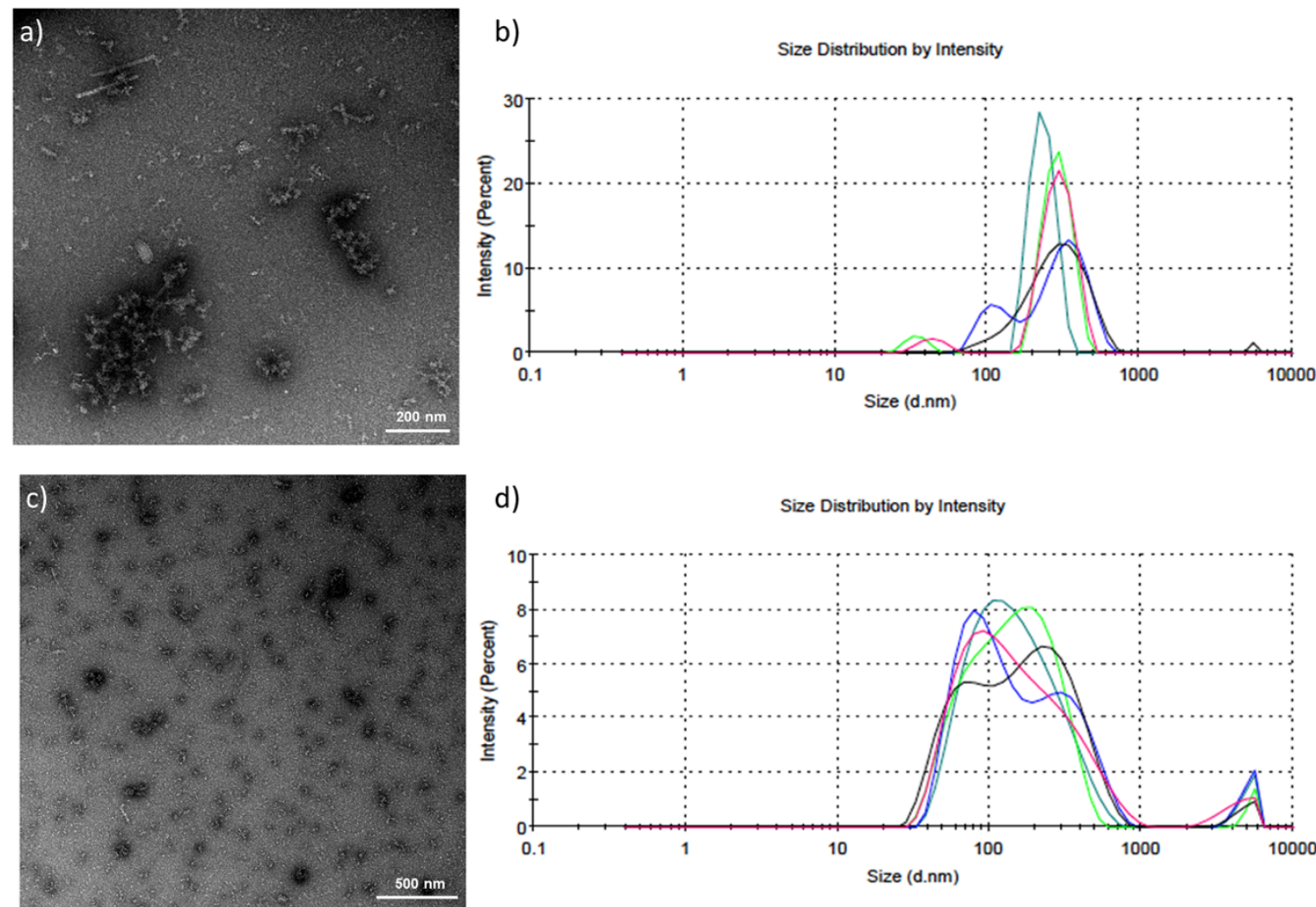

Figure 2. Transmission electron microscopy images of (a) peptide 2 (bar $200 \mathrm{~nm}$ ) and (c) 3 (bar $500 \mathrm{~nm}$ ) stained with 2\% uranyl acetate. Particle size distribution by the intensity of (b) peptide 2 and (d) 3. Five independent measurements by dynamic light scattering were recorded per compound.

The ability of the vaccine peptides to elicit a humoral response against hookworm was investigated. BALB/c mice (10 mice/group) were orally immunised with vaccine candidates. The positive control group received peptide 1 formulated with cholera toxin subunit 
B (CTB), a potent mucosal adjuvant that is only approved for mouse studies due to its potential adverse effects in other animal species and the negative control group received PBS. Following weekly oral dosing for 6 weeks (day 49), immunized mice were subcutaneously challenged with $500 \mathrm{~N}$. brasiliensis third-stage larvae (L3) and left for 7 days. Peptide-based vaccines against hookworm not only need to induce the production of antibodies against the p3 peptide but those antibodies also need to recognize the parent $N$. americanus and $N$. brasiliensis proteins, $N a$-APR-1 and $N b$-APR1 , respectively. Recombinant $\mathrm{Na}$-APR-1 is accessible $^{42}$; however, recombinant $N b$-APR-1 is presently only available in the native form in $N$. brasiliensis excretory/secretory products
(Nbr ESP).$^{43}$ Similar IgG antibody titers against p3, Na-APR-1 and $N b r$ ESP were detected in mice treated with peptides $\mathbf{2}$ and $\mathbf{3}$ and positive control CTB +1 , respectively (Figure 3). All mice immunized with peptides $\mathbf{2}$ and $\mathbf{3}$ produced antibodies against the hookworm peptides and parent proteins, with similar titers to positive control mice. No quantifiable induction of a natural immune response to the peptide/proteins was seen in the negative control group for at least 7 days following $N$. brasiliensis challenge (Figure 3d-f, PBS group). Natural immune responses may be seen anywhere up to two weeks following infection, but the vaccinated groups in this study produced higher antibody titers after just 7 days.
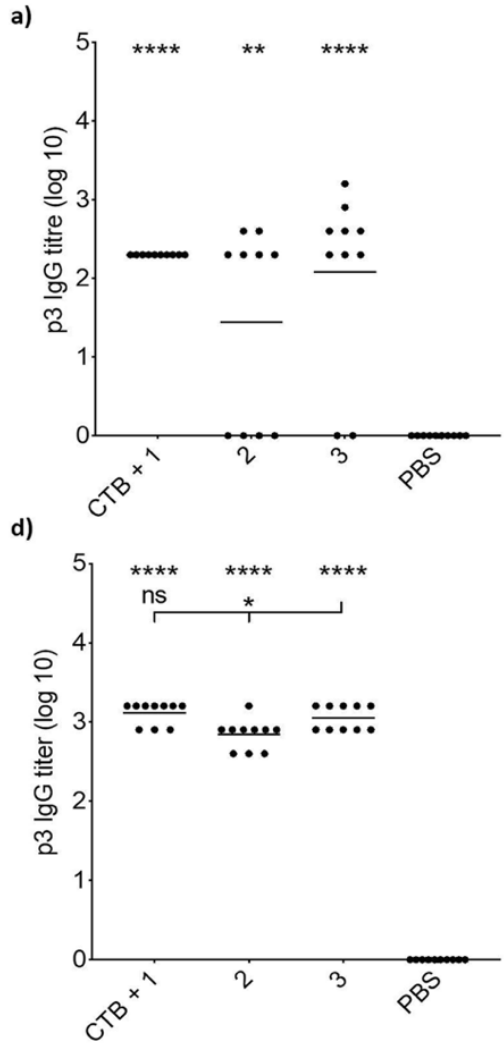
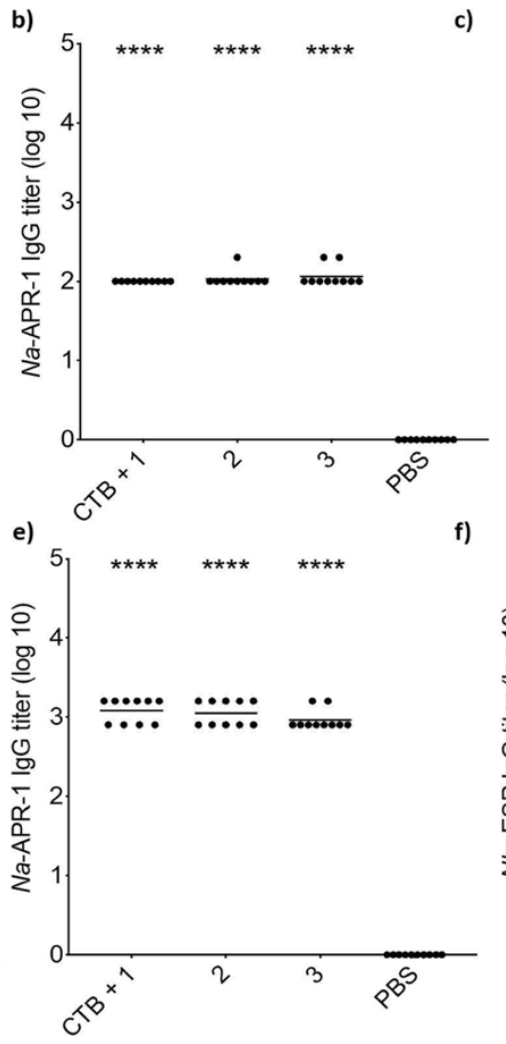

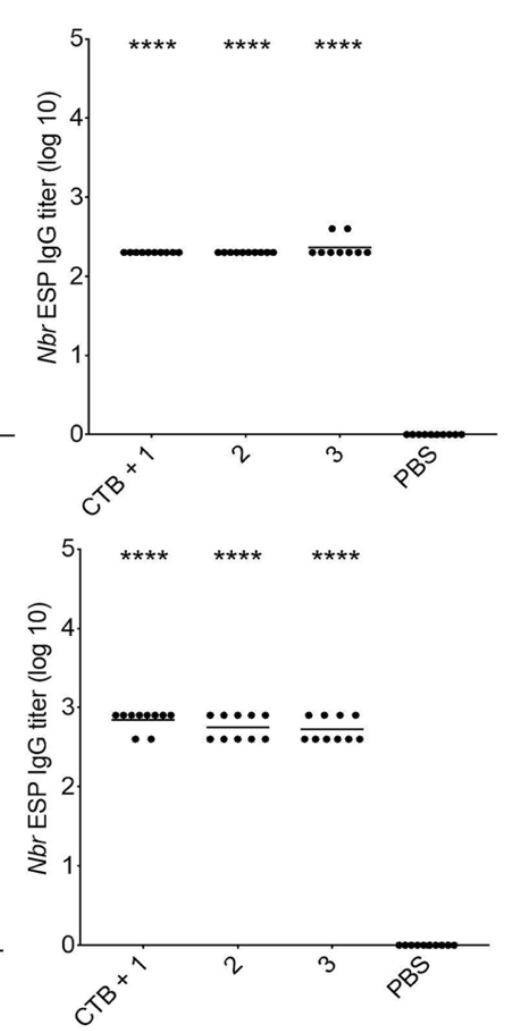

Figure 3. p3-specific, Na-APR-1 and Nbr ESP IgG antibody titers from pre-challenge blood (day 48) and 7 days postchallenge with N. brasiliensis (day 56). (a) p3-specific serum IgG titers at day 48; (b) Na-APR-1-specific serum IgG titers at day 48; (c) Nbr ESP-specific serum IgG titers at day 48;(d) p3-specific serum IgG titers at day 56; (e) Na-APR-1-specific serum IgG titers at day 56; (f) Nbr ESP-specific serum IgG titers at day 56. Each point represents an individual inbred BALB/c mouse $(n=10)$. Statistical analysis was performed for mice immunized with peptide antigens in comparison to mice treated with PBS (there were no statistical significant differences between immunized groups except that shown on panel (d)); $n s$, $p>0.05 ; * *, p<0.01 ; * * *, p<0.001, * * * *, p<0.0001$.

Adult worms were collected from the small intestine and eggs counted from faecal samples 7 days after infection (day 56). Mean adult worm burden was significantly reduced in mice vaccinated with 2 ( $85 \%$ reduction), $3(89 \%)$ and CTB + $1(98 \%)$ compared to negative control mice (Figure 4). Faecal egg burden was also significantly lower in mice vaccinated with $\mathbf{2}$ 
(84\%), 3 (75\%) and CTB + 1 (98\%). While there was no significant difference in worm burden between mice that received the unnatural and natural amino acid-based delivery systems (i.e. peptide $\mathbf{2}$ vs $\mathbf{3}$ ), the pHAA-based vaccine (3) has other notable advantages, as it is fully biodegradable with natural metabolites, composed of readily available natural amino acids, and is a fully defined single molecule without racemic moieties. There is not a distinct threshold of protection required for human helminth infections. What is generally accepted is that sterilizing immunity is unlikely to be achieved, and importantly, unnecessary to limit pathology. ${ }^{44}$ In helminth infections, and notably hookworm disease, there is a clear correlation between infection intensity and morbidity. The more worms that are present, the greater the blood loss and accompanying iron-deficiency anaemia (IDA). IDA is responsible for the pathogenesis of hookworm disease, so limiting adult worm burdens without necessarily eliminating the infection altogether is required to achieve an effective anti-disease vaccine. The ability of a host to tolerate blood loss induced by feeding hookworms is also dependent on the nutritional status of the host and their ability to replenish lost blood. ${ }^{45}$
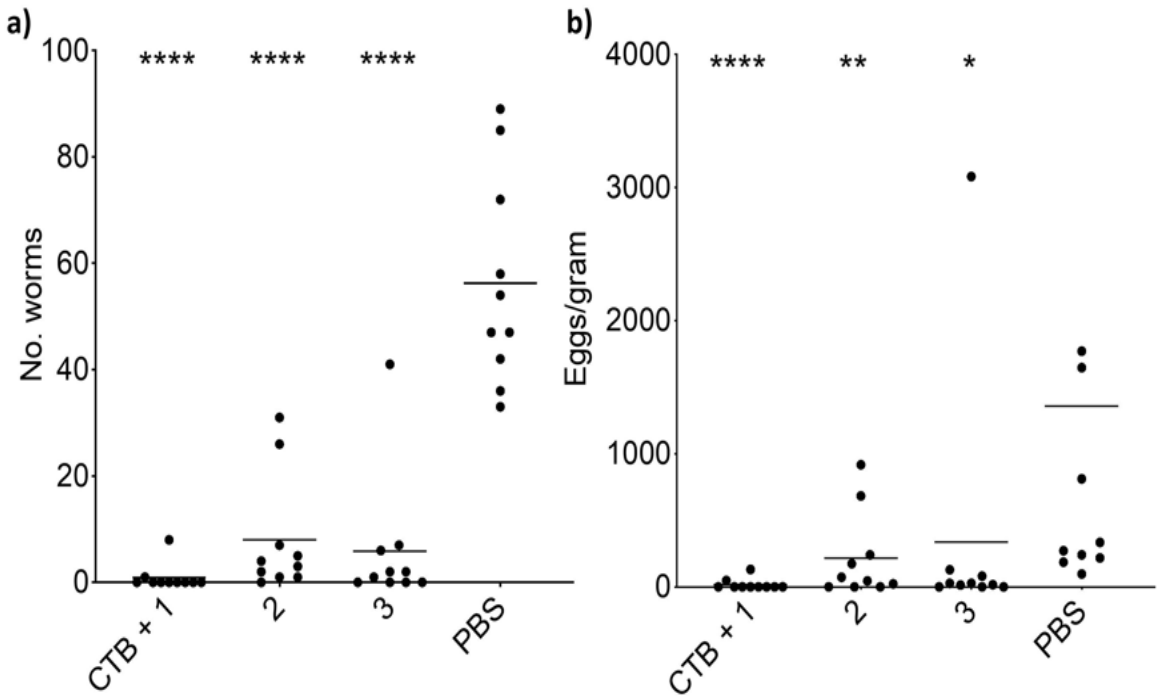

Figure 4. Peptides 1, 2 and 3 induced significant reductions in parasite burden after challenge with Nippostrongylus brasiliensis. The number of worms in the small intestine (a) and eggs in feces collected from the colon (b) were significantly reduced compared to control mice that received just PBS. Egg burden was calculated based on the number of eggs in $1 \mathrm{~g}$ of feces. Horizontal bars represent the mean of each group. Statistical analysis was performed for mice immunized with peptide antigens in comparison to mice treated with PBS; $n s, \mathrm{p}>0.05 ; *, p<0.05 ; * *, p<0.01 ; * * * *, p<0.0001$.

\section{Conclusion}

Effective, non-toxic, adjuvating delivery systems for oral peptide vaccines do not exist, and the development of a universal adjuvant has been one factor limiting mucosal vaccination. Here, we produced single component, self-assembling, nanoparticle delivery systems that protected mice against a model hookworm infection. While classical, multicomponent delivery systems, such as polymers or modified liposomes, are commonly used in vaccine design we demonstrated that a single moleculebased delivery system for oral administration can be effective. In comparison to unnatural lipid-based vaccine candidates, the self-adjuvating pHAA system is easily and inexpensively produced, and properties (e.g. water solubility, conformational behaviour, etc.) of the pHAA unit can be adjusted as required by altering length and amino acid composition. The pHAA-based vaccine presented here is the first construct built entirely from natural amino acids that has been effective at inducing humoral immune response after oral administration.

\section{Financial}

This work was supported by the National Health and Medical Research Council, Australia [NHMRC Program Grant 1132975 awarded to IT and AL]. SB is supported by a University of Queensland 
Research Training Program Scholarship (UQ RTP). RME was supported by an "Early Postdoc Mobility" fellowship (P2ZHP3_161693) from the Swiss National Science Foundation. AL is supported by an NHMRC Senior Principal Research Fellowship (1117504). The funding bodies had no role in the study design, data collection or analysis, the decision to publish, or the preparation of the manuscript.

\section{Ethics Statement}

All experimental work involving animals was approved by the James Cook University (JCU) animal ethics committee (ethics approval numbers A2300 and A2433). Animals were raised in the JCU animal facility under normal conditions with regulated temperature and lighting (12 h light/dark cycle) with free access to pelleted food and water in compliance with the Australian Code of Practice for the Care and Use of Animals for Scientific Purposes and the Queensland Animal Care and Protection Act.

\section{Acknowledgements}

The authors acknowledge the facilities and the scientific and technical assistance of the Australian Microscopy \& Microanalysis Research Facility at the Centre for Microscopy and Microanalysis, The University of Queensland. We thank Dr RJ Nevagi for providing the TEM imaging. We thank staff in the AITHM Cairns and Townsville animal facilities for animal husbandry. Special thanks go to Dr M Pearson for providing recombinant $\mathrm{Na}$-APR-1 protein.

\section{Conflict of Interests}

The authors declare no conflicts of interest. For signed statements, please contact the journal office: editor@precisionnanomedicine.com

Quote this article as: Bartlett S, Skwarczynski M, Xie X, Toth I, Loukas A, Eichenberger RM,

Development of natural and unnatural amino acid delivery systems against hookworm infection, Precis. Nanomed. 2020 January;3(1):471-482, https://doi.org/10.33218/prnano3(1).191210.1

\section{References}

1. Loukas, A.; Hotez, P. J.; Diemert, D.; Yazdanbakhsh, M.; McCarthy, J. S.; Correa-Oliveira, R.; Croese, J.; Bethony, J. M. Hookworm infection. Nat Rev Dis Primers 2016, 2, 16088.

2. Bethony, J.; Chen, J.; Lin, S.; Xiao, S.; Zhan, B.; Li, S.; Xue, H.; Xing, F.; Humphries, D.; Yan, W.; Chen, G.; Foster, V.; Hawdon, J. M.; Hotez, P. J. Emerging patterns of hookworm infection: influence of aging on the intensity of Necator infection in Hainan Province, People's Republic of China. Clin Infect Dis 2002, 35, 1336-44.

3. Purcell, A. W.; McCluskey, J.; Rossjohn, J. More than one reason to rethink the use of peptides in vaccine design. Nat. Rev. Drug Discovery 2007, 6, 404-414.

4. $\quad$ Skwarczynski, M.; Toth, I. Peptide-based synthetic vaccines. Chemical Science 2016, 7, 842854.

5. Nevagi, R. J.; Toth, I.; Skwarczynski, M. 12 - Peptide-based vaccines. In Peptide Applications in Biomedicine, Biotechnology and Bioengineering, Koutsopoulos, S., Ed. Woodhead Publishing: 2018; pp 327-358.

6. Schulze, K.; Ebensen, T.; Chandrudu, S.; Skwarczynski, M.; Toth, I.; Olive, C.; Guzman, C. A. Bivalent mucosal peptide vaccines administered using the LCP carrier system stimulate protective immune responses against Streptococcus pyogenes infection. Nanomed.-Nanotechnol. Biol. Med. 2017, $13,2463-2474$.

7. Sedaghat, B.; Stephenson, R. J.; Giddam, A. K.; Eskandari, S.; Apte, S. H.; Pattinson, D. J.; Doolan, D. L.; Toth, I. Synthesis of Mannosylated Lipopeptides with Receptor Targeting Properties. Bioconjugate Chem. 2016, 27, 533-548.

8. Ahmad Fuaad, A. A.; Roubille, R.; Pearson, M. S.; Pickering, D. A.; Loukas, A. C.; Skwarczynski, M.; Toth, I. The use of a conformational cathepsin D-derived epitope for vaccine development against Schistosoma mansoni. Bioorg. Med. Chem. 2015, 23, 1307-12.

9. Skwarczynski, M.; Toth, I. Lipid-core-peptide system for self-adjuvating synthetic vaccine delivery. In Bioconjugation Protocols, Mark, S. S., Ed. Humana Press: 2011; Vol. 751, pp 297-308. 
10. Zhong, W.; Skwarczynski, M.; Toth, I. Lipid Core Peptide System for Gene, Drug, and Vaccine Delivery. Aust. J. Chem. 2009, 62, 956-967.

11. Bartlett, S.; Skwarczynski, M.; Toth, I. Lipids as activators of innate immunity in peptide vaccine delivery. Curr. Med. Chem. 2020, accepted 25.10.2018; DOI: $10.2174 / 0929867325666181026100849$.

12. Skwarczynski, M.; Dougall, A. M.; Khoshnejad, M.; Chandrudu, S.; Pearson, M. S.; Loukas, A.; Toth, I. Peptide-based subunit vaccine against hookworm infection. PloS one 2012, 7, e46870e46870.

13. Ahmad Fuaad, A. A. H.; Pearson, M. S.; Pickering, D. A.; Becker, L.; Zhao, G.; Loukas, A. C.; Skwarczynski, M.; Toth, I. Lipopeptide Nanoparticles: Development of Vaccines against Hookworm Parasite. ChemMedChem 2015, 10, 1647-1654.

14. Zhao, G.; Chandrudu, S.; Skwarczynski, M.; Toth, I. The application of self-assembled nanostructures in peptide-based subunit vaccine development. Eur. Polym. J. 2017, 93, 670-681.

15. Skwarczynski, M.; Toth, I. Recent advances in peptide-based subunit nanovaccines. Nanomedicine (London, U. K.) 2014, 9, 2657-2669.

16. Nandedkar, T. D. Nanovaccines: recent developments in vaccination. J. Biosci. 2009, 34, 9951003.

17. Marasini, N.; Skwarczynski, M.; Toth, I. Oral delivery of nanoparticle-based vaccines. Expert Rev. Vaccines 2014, 13, 1361-76.

18. des Rieux, A.; Fievez, V.; Garinot, M.; Schneider, Y. J.; Preat, V. Nanoparticles as potential oral delivery systems of proteins and vaccines: A mechanistic approach. J. Controlled Release 2006, $116,1-27$.

19. Marasini, N.; Giddam, A. K.; Ghaffar, K. A.; Batzloff, M. R.; Good, M. F.; Skwarczynski, M.; Toth, I. Multilayer engineered nanoliposomes as a novel tool for oral delivery of lipopeptide-based vaccines against group A Streptococcus. Nanomedicine-Uk 2016, 11, 1223-1236.

20. Faruck, M. O.; Zhao, L.; Hussein, W. M.; Khalil, Z. G.; Capon, R. J.; Skwarczynski, M.; Toth, I. Polyacrylate-Peptide Antigen Conjugate as a Single-Dose Oral Vaccine against Group A Streptococcus. Vaccines 2020, 8, 23.

21. Chan, A.; Hussein, W. M.; Ghaffar, K. A.; Marasini, N.; Mostafa, A.; Eskandari, S.; Batzloff, M. R.; Good, M. F.; Skwarczynski, M.; Toth, I. Structure-activity relationship of lipid core peptidebased Group A Streptococcus vaccine candidates. Bioorganic \& Medicinal Chemistry 2016, 24, 3095 3101 .

22. Zaman, M.; Chandrudu, S.; Giddam, A. K.; Reiman, J.; Skwarczynski, M.; McPhun, V.; Moyle, P. M.; Batzloff, M. R.; Good, M. F.; Toth, I. Group A Streptococcal vaccine candidate: contribution of epitope to size, antigen presenting cell interaction and immunogenicity. Nanomedicine (Lond) 2014, 9, 2613-24.

23. Skwarczynski, M.; Zhao, G.; Boer, J. C.; Ozberk, V.; Azuar, A.; Cruz, J. G.; Giddam, A. K.; Khalil, Z. G.; Pandey, M.; Shibu, M. A.; Hussein, W. M.; Nevagi, R.; Batzloff, M. R.; Wells, J. W.; Capon, R. J.; Plebanski, M.; Good, M. F.; Toth, I. Poly(amino acids) as a potent self-adjuvating delivery system for peptide-based nanovaccines. Sci $A d v \mathbf{2 0 2 0}$, 6, eaax2285.

24. Azizi, A.; Kumar, A.; Diaz-Mitoma, F.; Mestecky, J. Enhancing Oral Vaccine Potency by Targeting Intestinal M Cells. PLOS Pathogens 2010, 6, e1001147.

25. Williamson, A. L.; Lecchi, P.; Turk, B. E.; Choe, Y.; Hotez, P. J.; McKerrow, J. H.; Cantley, L. C.; Sajid, M.; Craik, C. S.; Loukas, A. A multi-enzyme cascade of hemoglobin proteolysis in the intestine of blood-feeding hookworms. J. Biol. Chem. 2004, 279, 35950-35957.

26. Ranjit, N.; Zhan, B.; Hamilton, B.; Stenzel, D.; Lowther, J.; Pearson, M.; Gorman, J.; Hotez, P.; Loukas, A. Proteolytic Degradation of Hemoglobin in the Intestine of the Human Hookworm Necator americanus. J. Infect. Dis. 2009, 199, 904-912.

27. Seid, C. A.; Curti, E.; Jones, R. M.; Hudspeth, E.; Rezende, W.; Pollet, J.; Center, L.; Versteeg, L.; Pritchard, S.; Musiychuk, K.; Yusibov, V.; Hotez, P. J.; Bottazzi, M. E. Expression, purification, and characterization of the Necator americanus aspartic protease-1 (Na-APR-1 (M74)) antigen, a component of the bivalent human hookworm vaccine. Human Vaccines \& Immunotherapeutics 2015, $11,1474-1488$. 
28. Pearson, M. S.; Pickering, D. A.; Tribolet, L.; Cooper, L.; Mulvenna, J.; Oliveira, L. M.; Bethony, J. M.; Hotez, P. J.; Loukas, A. Neutralizing Antibodies to the Hookworm Hemoglobinase NaAPR-1: Implications for a Multivalent Vaccine against Hookworm Infection and Schistosomiasis. The Journal of Infectious Diseases 2010, 201, 1561-1569.

29. Bartlett, S.; Eichenberger, R. M.; Nevagi, R. J.; Ghaffar, K. A.; Marasini, N.; Dai, Y.; Loukas, A.; Toth, I.; Skwarczynski, M. Lipopeptide-based oral vaccine against hookworm infection. The Journal of infectious diseases 2020, accepted 17.10.2019; DOI: 10.1093/infdis/jiz528.

30. Fuaad, A. A. H. A.; Skwarczynski, M.; Toth, I. The Use of Microwave-Assisted Solid-Phase Peptide Synthesis and Click Chemistry for the Synthesis of Vaccine Candidates Against Hookworm Infection. Methods Mol Biol 2016, 1403, 639-653.

31. Camberis, M.; Le Gros, G.; Urban Jr., J. Animal Model of Nippostrongylus brasiliensis and Heligmosomoides polygyrus. Current Protocols in Immunology 2003, 55, 19.12.1-19.12.27.

32. Giacomin, P.; Gordon, D.; Botto, M.; Daha, M.; D Sanderson, S.; Taylor, S.; Dent, L. The role of complement in innate, adaptive and eosinophil-dependent immunity to the nematode Nippostrongylus brasiliensis. 2008; Vol. 45, p 446-55.

33. Pearson, M. S.; Bethony, J. M.; Pickering, D. A.; de Oliveira, L. M.; Jariwala, A.; Santiago, H.; Miles, A. P.; Zhan, B.; Jiang, D.; Ranjit, N.; Mulvenna, J.; Tribolet, L.; Plieskatt, J.; Smith, T.; Bottazzi, M. E.; Jones, K.; Keegan, B.; Hotez, P. J.; Loukas, A. An enzymatically inactivated hemoglobinase from Necator americanus induces neutralizing antibodies against multiple hookworm species and protects dogs against heterologous hookworm infection. FASEB journal : official publication of the Federation of American Societies for Experimental Biology 2009, 23, 3007-3019.

34. Eichenberger, R. M.; Ryan, S.; Jones, L.; Buitrago, G.; Polster, R.; Montes de Oca, M.; Zuvelek, J.; Giacomin, P. R.; Dent, L. A.; Engwerda, C. R.; Field, M. A.; Sotillo, J.; Loukas, A. Hookworm Secreted Extracellular Vesicles Interact With Host Cells and Prevent Inducible Colitis in Mice. Frontiers in immunology 2018, 9, 850-850.

35. Skwarczynski, M.; Toth, I. Lipid-Core-Peptide System for Self-Adjuvanting Synthetic Vaccine Delivery. In Bioconjugation Protocols: Strategies and Methods, Mark, S. S., Ed. Humana Press: Totowa, NJ, 2011; pp 297-308.

36. Reitermann, A.; Metzger, J.; WiesmÜLler, K.-H.; Jung, G.; Bessler, W. G. Lipopeptide Derivatives of Bacterial Lipoprotein Constitute Potent Immune Adjuvants Combined with or Covalently Coupled to Antigen or Hapten. In Biological Chemistry Hoppe-Seyler, 1989; Vol. 370, p 343.

37. Skwarczynski, M.; A. Kamaruzaman, K.; Srinivasan, S.; Zaman, M.; Lin, I. C.; R. Batzloff, M.; F. Good, M.; Toth, I. M-Protein-derived Conformational Peptide Epitope Vaccine Candidate against Group A Streptococcus. Current Drug Delivery 2013, 10, 39-45.

38. Nevagi, R. J.; Dai, W.; Khalil, Z. G.; Hussein, W. M.; Capon, R. J.; Skwarczynski, M.; Toth, I. Structure-activity relationship of group A streptococcus lipopeptide vaccine candidates in trimethyl chitosan-based self-adjuvating delivery system. Eur. J. Med. Chem. 2019, 179, 100-108.

39. Jaberolansar, N.; Chappell, K. J.; Watterson, D.; Bermingham, I. M.; Toth, I.; Young, P. R.; Skwarczynski, M. Induction of high titred, non-neutralising antibodies by self-adjuvating peptide epitopes derived from the respiratory syncytial virus fusion protein. Scientific Reports 2017, 7.

40. Azmi, F.; Ahmad Fuaad, A. A.; Giddam, A. K.; Batzloff, M. R.; Good, M. F.; Skwarczynski, M.; Toth, I. Self-adjuvating vaccine against group A streptococcus: application of fibrillized peptide and immunostimulatory lipid as adjuvant. Bioorg. Med. Chem. 2014, 22, 6401-8.

41. Wang, T.; Jiang, H.; Zhao, Q.; Wang, S.; Zou, M.; Cheng, G. Enhanced mucosal and systemic immune responses obtained by porous silica nanoparticles used as an oral vaccine adjuvant: Effect of silica architecture on immunological properties. International Journal of Pharmaceutics 2012, 436, 351-358.

42. Pearson, M. S.; Bethony, J. M.; Pickering, D. A.; de Oliveira, L. M.; Jariwala, A.; Santiago, H.; Miles, A. P.; Zhan, B.; Jiang, D.; Ranjit, N.; Mulvenna, J.; Tribolet, L.; Plieskatt, J.; Smith, T.; Bottazzi, M. E.; Jones, K.; Keegan, B.; Hotez, P. J.; Loukas, A. An enzymatically inactivated hemoglobinase from Necator americanus induces neutralizing antibodies against multiple hookworm species and protects dogs against heterologous hookworm infection. FASEB J 2009, 23, 3007-19. 
43. Sotillo, J.; Sanchez-Flores, A.; Cantacessi, C.; Harcus, Y.; Pickering, D.; Bouchery, T.; Camberis, M.; Tang, S. C.; Giacomin, P.; Mulvenna, J.; Mitreva, M.; Berriman, M.; LeGros, G.; Maizels, R. M.; Loukas, A. Secreted proteomes of different developmental stages of the gastrointestinal nematode Nippostrongylus brasiliensis. Mol Cell Proteomics 2014, 13, 2736-51.

44. Haldeman, M. S.; Nolan, M. S.; Ng'habi, K. R. N. Human hookworm infection: Is effective control possible? A review of hookworm control efforts and future directions. Acta Trop. 2020, 201, 105214.

45. Moncayo, A. L.; Lovato, R.; Cooper, P. J. Soil-transmitted helminth infections and nutritional status in Ecuador: findings from a national survey and implications for control strategies. 2018, 8, e021319. 